\title{
Imagens dos cientistas Jean-Baptiste de Lamarck e Charles Darwin: o que alunos concluintes do ensino médio sabem sobre eles?
}

\author{
Eduarda Tais Breunig 1 \\ Aléxia Santos Amaral 2 \\ Andréa Inês Goldschmidt ${ }^{3}$
}

\begin{abstract}
RESUMO
A pesquisa buscou investigar as concepções de setenta e oito alunos de terceiro ano do ensino médio de escolas públicas, a respeito da imagem e do nome de dois cientistas importantes para a Biologia e as implicações destas relacionadas à Ciência, através de dois questionários, compostos por duas partes. Inicialmente foi aplicado o primeiro, que investigou o reconhecimento de cientistas através de imagens sem nomeação e uma segunda parte, contendo outras imagens dos cientistas; porém, nominadas. Os resultados mostraram que o uso de imagens ainda é restrito em sala de aula; não tendo sido reconhecidos de forma significativa nenhum dos cientistas, principalmente, quando não foi mencionado os nomes. Além disso, muitas concepções reducionistas sobre cientistas e sobre a ciência foram identificadas.
\end{abstract}

PALAVRAS-CHAVE: Cientistas. Educação em Ciências. Ensino de Ciências.

Images of scientists Jean-Baptiste de Lamarck e Charles

Darwin: what do high school graduates know about them?

\footnotetext{
ABSTRACT

${ }^{1}$ Mestranda no Programa de Pós Graduação Educação em Ciências: Química da Vida e Saúde, Santa Maria, RS, Brasil.E-mail: dudabreunig@hotmail.com

${ }^{2}$ Graduanda em Ciências Biológicas. Universidade Federal de Santa Maria, Palmeira das Missões, RS, Brasil. Email: alexiaamaral79@ hotmail.com

${ }^{3}$ Doutora em Educação em Ciências, Professora Adjunto II, Universidade Federal de Santa Maria, Palmeira das Missões, RS, Brasil.E-mail: andreainesgold@gmail.com
} 
The research sought to investigate the conceptions of seventy-eight thirdyear high school students of public schools, about the image and name of two important scientists for Biology and the implications of these related to Science, through two questionnaires, composed of two parts. Initially the first was applied, which investigated the recognition of scientists through unnamed images and a second part having other images of scientists; however, nominated. The results showed that the use of images is still restricted in the classroom; not having been recognized in any significant way by any of the scientists, especially when the names were not mentioned. In addition, many reductionist conceptions of scientists and science have been identified.

KEYWORDS: Scientists. History of Science. Science teaching

$* * *$

\section{Introdução}

A importância da História e da Filosofia da Ciência (HFC) no ensino de Ciências tem sido ressaltada por diversos pesquisadores dos processos de educação, sendo que um dos principais resultados que emergem destas discussões é que a sua inserção pode desencadear várias melhorias para o ensino de Ciências. Martins (2006) e Silva e Martins (2009) reconhecem a relevância da HFC no ensino de Ciência, pois elas podem oferecer subsídios à aprendizagem de teorias científicas, além de possibilitar discussões relevantes sobre a natureza do conhecimento científico, contribuindo para uma melhor compreensão da própria Natureza da Ciência $(\mathrm{NdC})$, da relação entre a ciência e a sociedade, da percepção da ciência como atividade humana, assim como a falibilidade dos cientistas, entre outros.

A Natureza da Ciência - NdC constitui uma linha investigativa dentro do campo de estudos da História e Filosofia da Ciência - HFC, e conceituamos aqui como um conjunto de elementos que tratam da construção, estabelecimento e organização do conhecimento científico, envolvendo desde questões internas, tais como método científico e relação 
entre experimento e teoria, até questões externas, como a influência de elementos sociais, culturais, religiosos e políticos na aceitação ou rejeição de ideias científicas (MOURA, 2014).

Desta forma, tal inserção pode favorecer a desconstrução de visão de ciência distorcida e equivocada, como por exemplo, de que a ciência é neutra, que detém um critério absoluto de verdade, que é afastada de sentimentos, linear e cumulativa, dentre outras (EL-HANI, 2006); SILVA, 2009).

Brando e colaboradores (2012) afirma que discussões históricas contribuem para superar o ensino fragmentado, possibilitando uma abordagem interdisciplinar. Além disso, pode possibilitar um ensino mais contextualizado e crítico.

Melzer e Aires (2015) discutem que o desejável é que a abordagem HFC possibilite a compreensão de como os fatos narrados foram produzidos, quais indivíduos estiveram envolvidos nessa produção e como esses fatos estão interligados com os aspectos sociais, políticos e econômicos de determinada época.

Silva e Teixeira (2009) apontam algumas vantagens do uso da História da Ciência: a) organiza e dá sentido às informações aprendidas, tornando-as relevantes; b) ao mostrar a ciência como um edifício em construção, a História da Ciência tira a visão arrogante de que ciência é algo acabado; c) permite ao estudante perceber que os cientistas passaram por dificuldades e também se enganavam; d) a ciência não é algo somente para poucos que possuem capacidades extraordinárias.

Dessa forma, concordamos com El-Hani (2006) quando afirma que não se trata somente de incluir uma abordagem dos processos de construção do conhecimento científico no Ensino de Ciências, mas de considerá-los no contexto histórico, filosófico e cultural em que a prática científica tem lugar, pois a inserção da HFC pode (I) humanizar as ciências, conectando-as com preocupações pessoais, éticas, culturais e políticas; (II) tornar as aulas de ciências mais desafiadoras e estimular o desenvolvimento de habilidades de 
raciocínio e pensamento crítico; (III) promover uma compreensão mais profunda e adequada dos próprios conteúdos científicos, entre outros.

Duarte et al. (2010) afirma que a presença da HFC nas salas de aula pode auxiliar em uma melhor compreensão dos conceitos elaborados pela ciência, expondo que esses conceitos são influenciados por aspectos históricos, sociais, políticos e econômicos. Essa inclusão pode facilitar o conhecimento da ciência sobre outra perspectiva, fazendo com que estudar ciência se torne mais atraente, despertando assim o interesse dos alunos. Pensar no ensino de Ciências nesta perspectiva, possibilita ao aluno compreender a Ciência em seus diversos aspectos sociais, culturais, tecnológicos, religiosos e políticos.

Martins (2006) comenta que o estudo histórico de como um cientista realmente desenvolveu sua pesquisa, ensina mais sobre o real processo científico do que qualquer manual de metodologia científica. Ou seja, mostra que a construção científica é feita de maneira gradativa com erros e acertos aonde seu processo deve ser considerado. Assim, como a HFC deve ser estudada, a biografia dos cientistas igualmente deve se fazer presente, e quando possível, até reproduzir experimentos históricos, como estratégia pedagógica.

Frade (2014) em sua pesquisa sobre a Natureza da Ciência em livros didáticos de biologia, evidenciou que os cientistas são pouco comentados nas obras, com informações escassas quanto a seu trabalho e a sua vida, se restringindo a colocação de datas de nascimento e falecimento, sua nacionalidade e/ou local de nascimento e/ou local que desenvolveu seu trabalho, sem possibilitar enfatizar o contexto sócio, histórico e cultural destes, de modo a contribuir para o avanço da ciência, o que pode influenciar muito na visão reducionista que os estudantes possuem dos mesmos. O autor ainda afirma que um fator de grande contribuição para entender como era o cientista é por meio da imagem (foto) do mesmo. Quando colocada no livro didático, constitui um fator necessário para que o discente possa conhecer mais do pesquisador e se interessar pelo seu trabalho. 
É importante salientar que a HFC não pode ser reduzida simplesmente a alguns dados biográficos dos cientistas. Isso não contribui para o entendimento da construção do conhecimento científico, nem mesmo para os aspectos sociais, culturais e econômicos envolvidos nessa abordagem. Sequeira e Leite (1988) alertam que simplificar a História da Ciência apenas aos dados biográficos pode ocasionar uma visão tendenciosa de que a mesma restringe-se apenas a nomes e a datas. Tal situação, pode fazer com que alunos não tenham informações importantes sobre estes cientistas de modo a reconhecerem os mesmos e compreenderem o papel deles na construção do conhecimento, uma vez que não é feita uma contextualização dos aspectos históricos.

Sobre essa dimensão versará o foco desse trabalho, onde é relatado um pouco da história da ciência de dois cientistas importantes relacionados à biologia. A pesquisa buscou investigar as concepções de alunos de terceiro ano do ensino médio a respeito da imagem e do nome desses dois cientistas importantes: Jean-Baptiste de Lamarck e Charles Darwin. Após a pesquisa, foi realizada uma apresentação sobre cada cientista, relatando sua vida e obra, a fim de elucidar aos alunos por meio da História da Ciência como realmente tais conhecimentos foram construídos.

\section{Trajetória metodológica}

Considerando a forma de coleta de dados, a análise utilizada e o uso do referencial teórico, trata-se de uma pesquisa qualitativa, a partir do uso de um questionário semiestruturado acerca do conhecimento e identificação de dois cientistas importantes na Biologia: Jean-Baptiste de Lamarck e Charles Darwin, que aparecem em livros de Biologia do Ensino Médio.

Bogdan e Biklen (2006) caracterizam a pesquisa qualitativa como tendo o ambiente natural como a principal fonte de dados, os quais são basicamente descritivos; tendo uma íntima relação com o pesquisador, pois ele é o principal instrumento; valoriza os processos aos resultados e 
perspectivas dos participantes e, por fim, analisa os dados de forma indutiva, dentro de um quadro teórico.

Já, a entrevista semiestruturada é aquela que parte de certos questionamentos básicos que interessam à pesquisa e oferecem um amplo campo de interrogativas que são fruto de novas hipóteses que vão surgindo à medida que se recebem as respostas do aluno, sendo que o aluno começa a participar da elaboração do conteúdo da pesquisa (NOGUEIRA-MARTINS 2004).

Trata-se de uma pesquisa de iniciação científica, desenvolvida no segundo semestre do ano de 2018, e que envolveu discentes de três turmas do terceiro ano do Ensino Médio, totalizando 78 participantes, em três escolas públicas do município de Palmeira das Missões, RS.

Os alunos foram convidados a participarem da pesquisa, assinando juntamente aos familiares, um termo livre e esclarecido.

O instrumento de investigação continha duas partes, uma respondida em um primeiro momento, e a segunda parte, respondida posteriormente após o término da primeira. Na parte 1, o questionário foi composto por quatro imagens ilustrativas dos cientistas, sem os seus nomes; e, abaixo de cada imagem, três questões semiestruturadas (fechadas e abertas), envolvendo (a) quem se referia a imagem; (b) se tratava ou não de um cientista; e (c) quais as justificativas para tal resposta. A segunda parte envolvia outras duas imagens dos mesmos cientistas selecionados; porém, apresentava os nomes deles. Nesse segundo momento, foram questionados: (a) se os discentes conheciam o cientista pela imagem e/ou pelo nome; (b) se conheciam suas contribuições para a ciência, e; (c) quais eram estas contribuições.

Após isso, os questionários recolhidos, foram tabulados, sendo calculadas as frequências e discutidos os resultados. Não se levou em consideração o sexo dos alunos, uma vez que não era objetivo de comparações. A faixa etária dos alunos variou entre 17 e 19 anos. 
Para a análise dos resultados provenientes das questões abertas presentes no questionário, seguiram-se os critérios de investigação para a análise de conteúdo, proposto por Bardin (2011). De acordo com a autora, a categorização é uma operação de classificação de elementos constitutivos de um conjunto, por diferenciação e, em seguida, por reagrupamento segundo o gênero (analogia). Deste modo, a análise de conteúdo categorial é alcançada por operações de desmembramento do texto em unidades, em categorias, segundo agrupamentos analógicos, e caracteriza-se por um processo estruturalista que classifica os elementos segundo a investigação sobre o que cada um deles tem em comum. Constituiu o corpus de análise os setenta e oito questionários aplicados e a categorização que se deu a posteriori.

\section{Resultados e discussões}

Ao analisar os resultados referentes à primeira parte do questionário, em que foram apresentadas apenas as imagens dos cientistas, sem a identificação, verificou-se que os dois cientistas selecionados para a pesquisa, não foram reconhecidos pelos alunos. Já, no segundo questionário, em que eram apresentadas as imagens seguidas dos nomes dos pesquisadores, os resultados mostraram que os alunos identificaram de forma pouco significativa os mesmos; e além disso, a maioria dos participantes, não reconhece os feitos importantes desses dois cientistas, demonstrando que não é apenas a imagem que não é trabalhada, mas também as discussões e apresentações sobre eles numa abordagem histórica, quase não se fazem presentes no ensino de ciências.

A Tabela 1 apresenta os percentuais analisados para a primeira parte do questionário, contendo a imagem, sem o nome do cientista Jean-Baptiste Pierre Antoine de Monet e a Tabela 2 apresenta os resultados encontrados para a segunda parte do questionário, quando além da imagem, foi fornecido o nome do cientista. 
TABELA 1: Frequência para o reconhecimento de imagens do cientista Jean-

Baptiste Pierre Antoine de Monet, sem a identificação.

\begin{tabular}{|c|c|c|c|c|c|}
\hline Imagem & \multicolumn{2}{|c|}{ Quem é? } & É cientista & Por quê? & $\%$ \\
\hline & \multirow{4}{*}{\multicolumn{2}{|c|}{$\begin{array}{c}\text { Não respondeu } \\
\quad 85,90 \%\end{array}$}} & $\begin{array}{c}\text { Sim } \\
21,80 \%\end{array}$ & Não respondeu & 21,80 \\
\hline & & & \multirow{2}{*}{$\begin{array}{c}\text { Não } \\
26,92 \%\end{array}$} & Não respondeu & 25,64 \\
\hline & & & & Parece imperador & 1,28 \\
\hline & & & \multicolumn{2}{|c|}{ Não respondeu } & 37,20 \\
\hline & \multirow{8}{*}{$\begin{array}{c}\text { Nominou } \\
14,08 \%\end{array}$} & \multirow{5}{*}{$\begin{array}{c}\text { Jean- } \\
\text { Baptiste } \\
\text { Pierre } \\
\text { Antoine } \\
\text { de } \\
\text { Monet } \\
8,96 \%\end{array}$} & \multirow{5}{*}{$\begin{array}{l}\text { Sim } \\
8,96 \%\end{array}$} & Não respondeu & 2,56 \\
\hline & & & & $\begin{array}{c}\text { Criou a lei do Uso } \\
\text { e desuso }\end{array}$ & 1,28 \\
\hline & & & & $\begin{array}{c}\text { Estudou a origem } \\
\text { e processos } \\
\text { evolutivos }\end{array}$ & 2,56 \\
\hline & & & & $\begin{array}{c}\text { Criou uma teoria } \\
\text { da evolução, uso e } \\
\text { desuso e } \\
\text { caracteres } \\
\text { adquiridos }\end{array}$ & 1,28 \\
\hline & & & & $\begin{array}{c}\text { Acreditava na } \\
\text { adaptação do } \\
\text { ambiente }\end{array}$ & 1,28 \\
\hline & & $\begin{array}{c}\text { Sigmund } \\
\text { Freud } \\
2,56 \% \\
\end{array}$ & \multicolumn{2}{|c|}{ Não respondeu } & 2,56 \\
\hline & & $\begin{array}{c}\text { Nelson } \\
\text { Mandela } \\
1,28 \% \\
\end{array}$ & \multicolumn{2}{|c|}{ Não respondeu } & 1,28 \\
\hline & & $\begin{array}{c}\text { Carl Marx } \\
1,28 \%\end{array}$ & \multicolumn{2}{|c|}{ Não respondeu } & 1,28 \\
\hline
\end{tabular}

Fonte: Elaborado pelas autoras (https://www.escritas.org/pt/estante/jean-baptiste-de-lamarck)

Ao pesquisarmos sobre o cientista Jean-Baptiste Pierre Antoine de Monet, que nasceu em 1744 e faleceu em 1829, mais conhecido como Lamarck, verificamos que os alunos reconheceram sem muita expressividade a imagem do mesmo (8,96\%), e quando o fizeram, poucos reconheceram suas contribuições para a ciência, sendo citadas entre elas os estudos sobre adaptação, a lei do uso e desuso e a herança dos caracteres adquiridos, embora em percentuais pouco significativos. Outros três nomes foram citados pelos alunos: Sigmund Freud, Nelson Mandela e Karl Marx.

Além de pouco reconhecido, obtivemos $69,24 \%$ de respostas não considerando o indivíduo da imagem como um cientista, tendo inclusive uma 
justificativa "parece um imperador". É notável que o aluno atribuiu esta resposta à Lamarck por meio de sua vestimenta, a qual aparenta ser pomposa e formal, indicando poder se tratar de um imperador e não de um cientista. Essa resposta nos faz refletir para o fato de qual é a vestimenta de um cientista, para esse aluno? Será que ele associa um cientista somente com um jaleco, em um laboratório? Pode ser que não, mas essa é uma imagem bastante comum segundo estudos na área. Sobre isto, Kosminsky e Giordan (2002) afirmam que esta percepção que os estudantes têm de um cientista deve estar atrelada ao que é visto na mídia e pelas expressões de sua cultura, cujos traços são parcialmente divulgados na mídia.

Pesquisas realizadas por Engelmann (2017) revelaram que para estudantes, os cientistas são homens de idade avançada, com barba, cabelos grisalhos, com vestimentas formais, ou ainda com jalecos brancos.

Quando ensinamos a história por trás de um conceito vemos que a ciência não é construída só através de acertos, e que esta se constrói por diversas tentativas, erros e várias contribuições de outros pesquisadores, até se chegar a uma resposta, e que esta também é mutável. Assim, é importante discutir com os alunos a respeito de Lamarck, de modo a terem consciência que o pensamento evolutivo iniciou muito antes de Darwin, e que Lamarck foi um dos estudiosos que se propôs a refletir sobre o tema. Por mais que algumas leis criadas por Lamarck não sejam aceitas hoje, estas contribuíram para o estudo de Darwin, e assim acontece ainda hoje, com todos os pesquisadores. Diante disso, é importante destacar que quando nos referimos à evolução, tanto Lamarck como Darwin, além de vários outros pesquisadores foram essenciais para a formulação dessas ideias que revolucionaram a biologia.

Ao serem questionados sobre as contribuições deste pesquisador presente na imagem, os alunos (8,96\%) apresentaram diferentes contribuições atreladas a Lamarck, entre elas, que estudou a origem e processos evolutivos $(2,56 \%)$, que criou a lei do uso e desuso $(1,28 \%)$, criação de uma teoria da evolução, também associada a lei uso e desuso (1,28\%); e, 
que o mesmo acreditava na adaptação do ambiente (1,28\%). Cabe salientar, que para Lamarck, esse processo de adaptação era possível, mas ocorria nos seres vivos, por meio de explicações físicas que eram particulares aos próprios indivíduos vivos. Lamarck, até muito tempo tinha uma visão fixista; ou seja, acreditava no fixismo, que afirmava que os seres vivos eram imutáveis, não sofriam evolução. Esta visão mudou a partir de suas publicações no período evolucionista, mas ainda assim não acreditava em uma evolução por seleção natural. (MARTINS; BAPTISTA, 2007).

Embora, as afirmações acima tenham sentido ao estudarmos Lamarck, Martins (2008) afirma que Lamarck, antes de publicar suas diversas obras relacionadas à evolução (a partir de 1800), tinha um pensamento análogo a quase todos os naturalistas de sua época; ou seja, acreditava que as espécies eram fixas, supondo que o meio era um fator responsável apenas pela produção de variedades.

Em seus estudos inclusive apresentou uma grande contribuição para o entendimento do vivo e não vivo? Para Lamarck, o Supremo autor de todas as coisas (Deus) criou a natureza. E esta era um conjunto de objetos metafísicos, constituído por leis e movimentos, observáveis nos corpos que existiam. Essa natureza deu origem progressivamente a todos os seres vivos, vegetais e animais, sem a intervenção divina. Lamarck procurou explicar a vida a partir dos fenômenos físicos conhecidos na época. Os movimentos executados no fluido desses pequenos corpos constituem desde então o que chamamos vida, e este movimento dos fluidos no interior do indivíduo iria, portanto, abrindo cavidades, tubos, canais, criando órgãos, que sofreriam mudanças nos diferentes animais, dando origem às diversas faculdades. Os animais mais simples gozariam apenas da irritabilidade. A natureza produziria gradativamente animais mais complexos, com sistema muscular, sistema nervoso, sentimento, inteligência. O tipo de reprodução estaria também ligado ao grau de perfeição. (LAMARCK, 1835 apud MARTINS, 2008). Lamarck assim descreveu as leis básicas da natureza que produzem a transformação dos animais: 
I. A vida, pelas suas próprias forças, tende continuamente a aumentar o volume de todo corpo que a possui, e a estender as dimensões de suas partes, até um limite que lhe é próprio. A vida tem uma tendência de aumentar a complexidade orgânica. (LAMARCK, 1835, vol. 1, p. 151).

II. A produção de um novo órgão em um corpo animal, resulta de uma nova necessidade que continue a se fazer sentir, e de um novo movimento que essa necessidade faz surgir e mantém. (LAMARCK, 1835, vol. 1, p. 152).

III. O desenvolvimento dos órgãos e sua força de ação estão em relação direta com o emprego desses órgãos. (LAMARCK, 1835, vol. 1, p. 152).

IV. Tudo o que foi adquirido, lavrado ou mudado, na organização dos indivíduos, durante o curso de sua vida, é conservado pela geração e transmitido aos novos indivíduos que provêm daqueles que experimentam essas mudanças. (LAMARCK, 1835, vol. 1, p 152).

Em sua fase evolucionista Lamarck teve uma mudança significativa de algumas ideias, entre elas o abandono de algumas concepções como a fixidez das espécies, a incapacidade da natureza de produzir a vida, ou mesmo, do próprio conceito de vida.

Embora as ideias de Lamarck faziam parte do pensamento "científico" vigente principalmente no final do século XVIII, ele se destacou por propor uma teoria de evolução coerente, de acordo com o contexto de sua época, que procurava explicar desde a origem da vida até o surgimento das faculdades superiores do homem através de leis naturais, sem a intervenção divina (MARTINS, 2008).

Martins e Baptista (2007) afirmam que é a partir de 1800, que Lamarck começou a construir o que conhecemos por lamarckismo para poder explicar a evolução, tendo esta sido muito difundida entre os pesquisadores 
da época e que propunha que os seres vivos apresentavam um gradualismo; ou seja, partiam dos mais simples para os mais complexos.

A partir destas ideias iniciais, Lamarck incorporou suas leis. De acordo com Martins e Baptista (2007) suas contribuições para a teoria evolutiva estão ao longo das suas obras: Recherches sur l'organisation des corps vivants; Philosophie zoologique e Histoire naturelle des animaux sans vertebres.

Essa teoria teve uma mínima aceitação entre os pesquisadores da época, ficando de lado até o início da teoria darwiniana.

TABELA 2: Frequências para o reconhecimento de imagens do cientista Jean-

Baptiste Pierre Antoine de Monet, com a identificação .

\begin{tabular}{|c|c|c|c|}
\hline & \multicolumn{2}{|l|}{ Questões } & $\%$ \\
\hline & \multicolumn{2}{|c|}{ Reconheci pela imagem } & 12,82 \\
\hline RCS & \multicolumn{2}{|c|}{ Não reconheci pela imagem } & 71,79 \\
\hline & \multicolumn{2}{|l|}{ Não respondeu } & 15,38 \\
\hline & \multicolumn{2}{|c|}{ Já ouvi falar o nome } & 38,46 \\
\hline & \multicolumn{2}{|c|}{ Nunca ouvi falar o nome } & 57,69 \\
\hline & \multicolumn{2}{|l|}{ Não respondeu } & 3,85 \\
\hline & \multicolumn{2}{|l|}{ Sei o que fez } & 16,67 \\
\hline & \multicolumn{2}{|l|}{ Não sei o que fez } & 69,23 \\
\hline & \multicolumn{2}{|l|}{ Não respondeu } & 14,10 \\
\hline & \multirow{4}{*}{ O que sabe dele? } & Não respondeu & 82,05 \\
\hline & & $\begin{array}{l}\text { Lamarckismo, lei do uso e } \\
\text { desuso, caracteres adquiridos }\end{array}$ & 14,10 \\
\hline & & Uso e desuso, girafa e pescoço & 1,28 \\
\hline & & $1^{\circ}$ teoria da evolução & 1,28 \\
\hline
\end{tabular}

Fonte: Elaborado pelas autoras (https://s10.lite.msu.edu/res/msu/botonl/b_online/e36/lamarck.htm)

Analisando os resultados da Tabela 2, percebemos que igualmente, os participantes afirmaram não reconhecer o indivíduo (71,79\%) na imagem, e quando questionado sobre o nome, apenas 38,46\% responderam ter conhecimento e apenas 16,67\% afirmaram saber das contribuições deste cientista, o que demonstra que não se trata apenas de recordar a imagem do cientista, mas o contexto de abordagem histórica também não se faz presente, pois as informações além de poucas, são por vezes até 
inadequadas, fazendo com que os alunos elaborem ideias reducionistas e até errôneas sobre o pensamento dos cientistas.

Os respondentes associaram Lamarck à evolução e especificamente a lei do uso e desuso. Foram mencionados principalmente "Lamarckismo, lei do uso e desuso, caracteres adquiridos" (14,10\%). Obtivemos as mesmas respostas encontradas para a primeira parte do questionário, embora com percentuais ainda menos significativos.

Martins (2007) esclarece que o Lamarckismo dizia que para que ocorresse a variação das espécies existia um processo de evolução. A partir dessa ideia, Lamarck estabeleceu que esse processo fosse regido por quatro leis, porém essas leis não são bem descritas por muitos autores. São bem conhecidas duas delas: a primeira lei é a de "uso e desuso" (embora, Lamarck nunca tenha utilizado essa expressão), que trazia a ideia de quanto mais se usasse um órgão do corpo ele tenderia a se desenvolver, ou quando menos se usasse ele tenderia a dissipar-se.

Para exemplificar esta lei, entre outros exemplos, Lamarck citou o famoso exemplo do alongamento do pescoço das girafas, dando origem à má interpretação e descrições equivocadas da sua teoria, geralmente encontrada nos livros didáticos.

A herança do adquirido: Tudo o que foi adquirido, traçado ou mudado na organização dos indivíduos, no decorrer de sua vida, é conservado pela geração e transmitido aos novos indivíduos que provêm daqueles que experimentaram essas mudanças. Desde que essas mudanças adquiridas sejam comuns aos dois sexos, ou àqueles que produziram esses novos indivíduos. (ALMEIDA; ROCHA FALCÃO, 2010, p. 653).

Almeida e Rocha Falcão (2005) afirmam que para Lamarck, a segunda lei trata-se da "herança dos caracteres adquiridos" (este pensamento já circulava na época, ou seja, é um equívoco dizer que Lamarck 
o criou), segundo esta lei todas as modificações sofridas serão passadas para os descendentes. Nessa lei Lamarck não deu muitas explicações sobre a transmissão dos caracteres adquiridos, abrindo assim outra brecha e dificultando a aceitação dessa teoria. Hoje em dia essa teoria não é aceita já que as características adquiridas não são hereditárias. Ao contrário da lei "do uso e desuso", que foi apresentada com um grande número de exemplos, Lamarck expôs esta lei rapidamente, não julgando que ela merecesse uma maior atenção (ALMEIDA; ROCHA FALCÃO, 2010). Por ironia, diversas vezes, a sua teoria tem sido reduzida nos termos desta formulação e apresentada de forma equivocada nos livros didáticos.

Sobre isto, Bizzo (1991) afirma, que a identificação direta e imediata entre a crença na herança das características adquiridas e a teoria de Lamarck é, antes de tudo, um equívoco. Pois, não se pode ligar a crença de toda uma época ao pensamento de uma só pessoa. O mesmo autor opina ser estranho que Lamarck seja lembrado, inclusive por professores de Biologia, como criador da crença na herança dos caracteres adquiridos - o que não é verdade - e não seja conhecido por ter sido o criador do termo biologia para designar uma nova disciplina - o que é verdade.

A sua teoria foi desenvolvida em uma das épocas mais revolucionárias da história, tanto em termos políticos, quanto intelectuais: a época da Revolução Francesa. Esse contexto muito provavelmente contribuiu para a ousadia de suas conjecturas (ALMEIDA; ROCHA FALCÃO, 2010). Embora não fosse objetivo central de Lamarck a evolução orgânica e nem tampouco a origem das espécies, a sua teoria é considerada, pelos historiadores da Biologia, como a primeira explicação sistemática da evolução dos seres vivos.

Diante das colocações dos alunos, é notável que a evolução abrange uma complexidade de fatores e deve ser abordada em sala de aula, atrelada à abordagem histórica, levando em consideração as ideias científicas que circulavam em cada época dos cientistas. Por meio da história da ciência, o aluno poderá compreender as fases e os diferentes fatores que influenciam e já influenciaram nos processos evolutivos. Trabalhar esse aspecto evolutivo, 
de maneira não fragmentada e mais exemplificada, pode vir a facilitar o processo de ensino-aprendizado, pois isso permitirá ao aluno entender o porquê e como tais mudanças evolutivas aconteceram.

Infelizmente, como afirmam Almeida e Rocha Falcão (2010) é frequente, nos livros didáticos de Biologia adotados no Brasil, a abordagem do tema evolução como concluído, desprovido de contextualização histórica para a compreensão, por parte dos alunos, de como os conceitos foram desenvolvidos ao longo do tempo. Neste contexto, podemos afirmar que a abordagem histórica geralmente é restrita, quando se faz presente.

Roque (2003) considera Lamarck um exemplo bem explícito de como a história da ciência é importante. Por mais que algumas leis de Lamarck não sejam aceitas hoje, não foi só Darwin que estudou e teve sucesso com seus trabalhos em evolução, Lamarck também obteve êxito, e seus estudos contribuíram para o estudo de Darwin, e assim acontece com todos os pesquisadores. Sem Lamarck, Darwin não teria chegado às conclusões expostas em A origem das espécies. Mesmo criticando-o fortemente a princípio, Darwin admite na sexta edição de sua obra o mérito lamarckiano como primeira tentativa de explicar a evolução (MARTINS, 2008).

Para a investigação com Charles Darwin, na primeira parte do questionário, foram usadas três imagens distintas, sem a nomeação, uma para cada época da vida, conforme observamos nas Tabelas 3,4 e 5 . Optamos por utilizar mais imagens, uma vez que é dada mais ênfase a este cientista em livros didáticos. Já, na Tabela 6, são apresentados os resultados encontrados, quando além da imagem, foi fornecido o nome do cientista. 
TABELA 3: Frequência para o reconhecimento de imagens do cientista Charles Darwin, sem a identificação (Imagem 1).

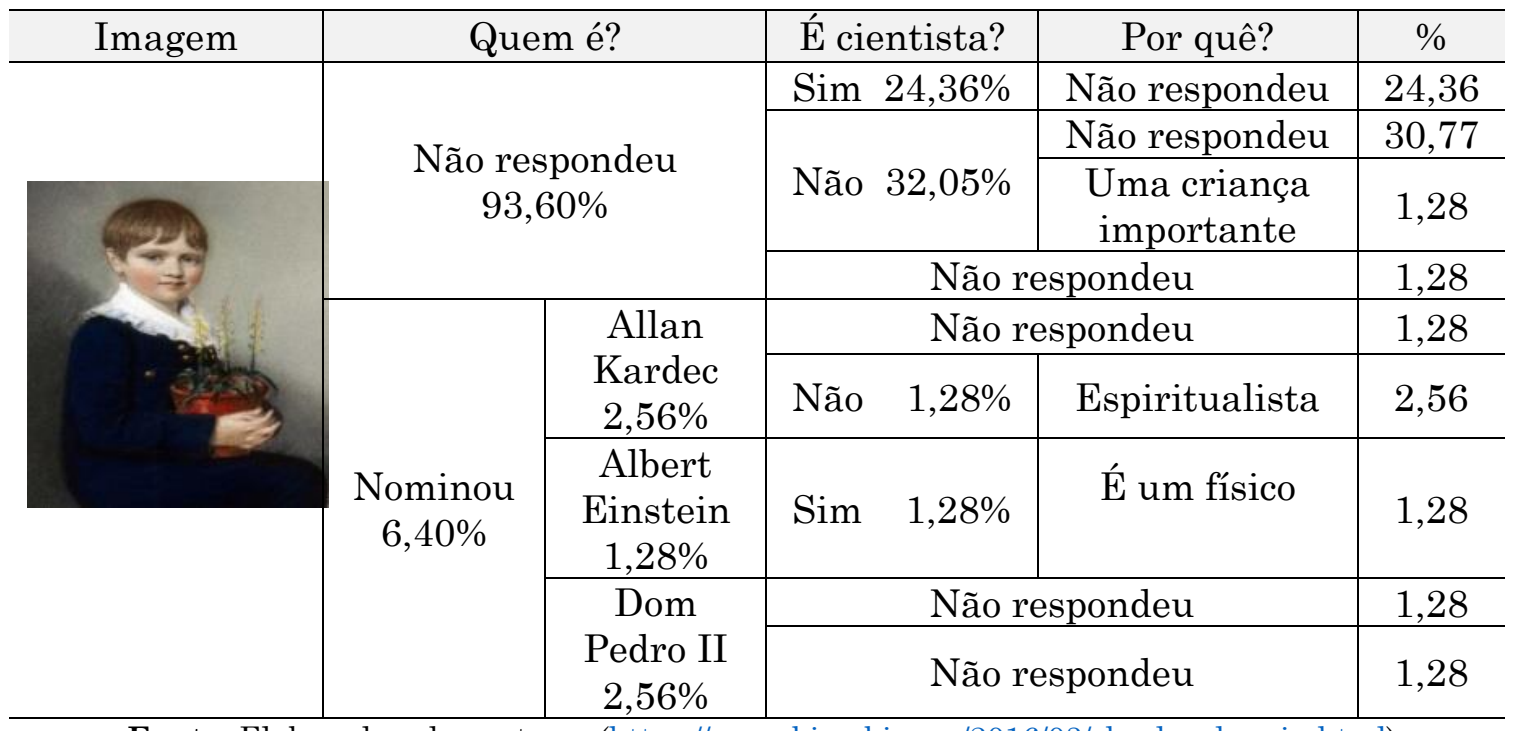

Fonte: Elaborado pelas autoras (https://www.bioorbis.org/2016/03/charles-darwin.html).

TABELA 4: Frequência para o reconhecimento de imagens do cientista Charles Darwin, sem a identificação (Imagem 2).

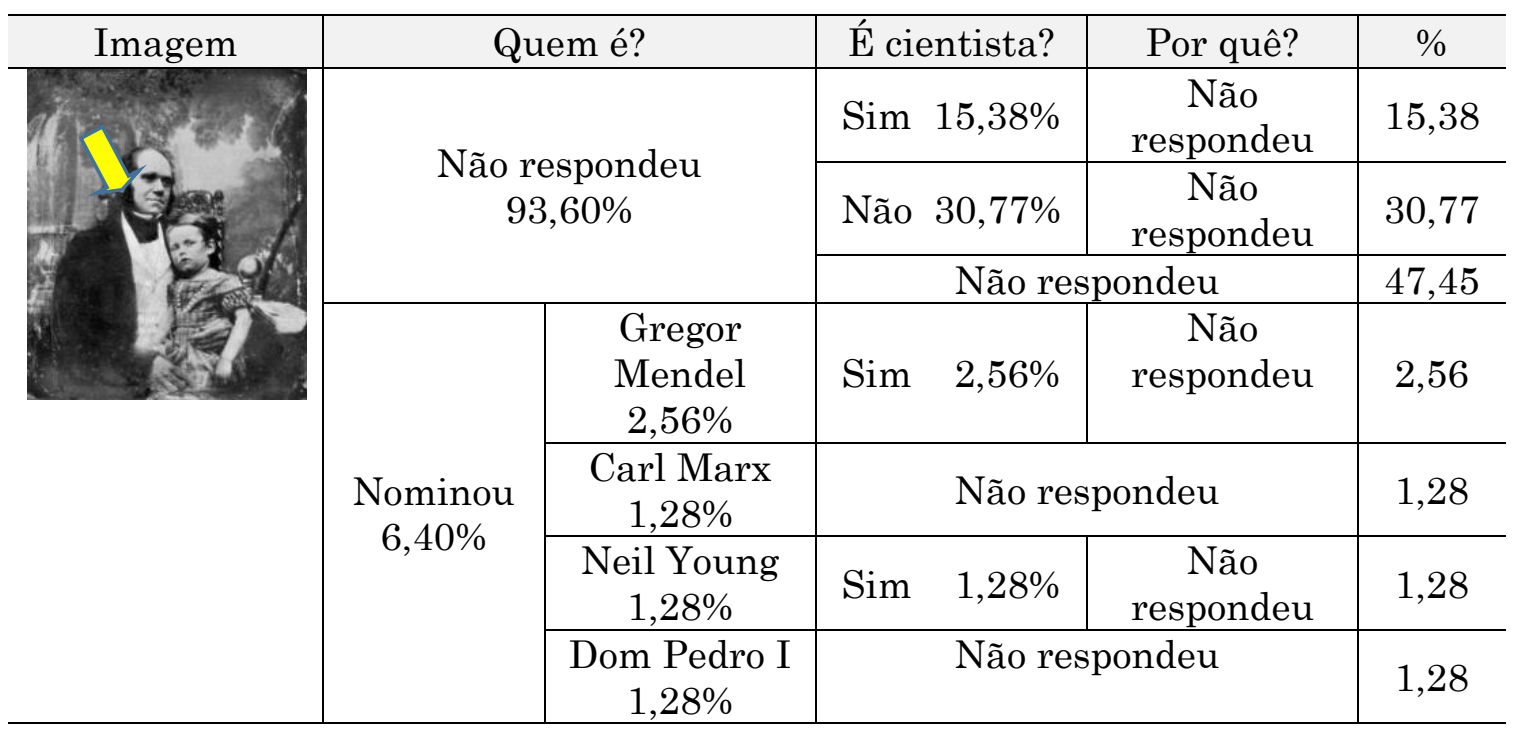

Fonte: Elaborado pelas autoras (https://pt.wikipedia.org/wiki/Ficheiro:Charles-Darwin-and-WilliamDarwin,-1842.png). 
TABELA 5: Frequência para o reconhecimento de imagens do cientista Charles Darwin, sem a identificação (Imagem 3).

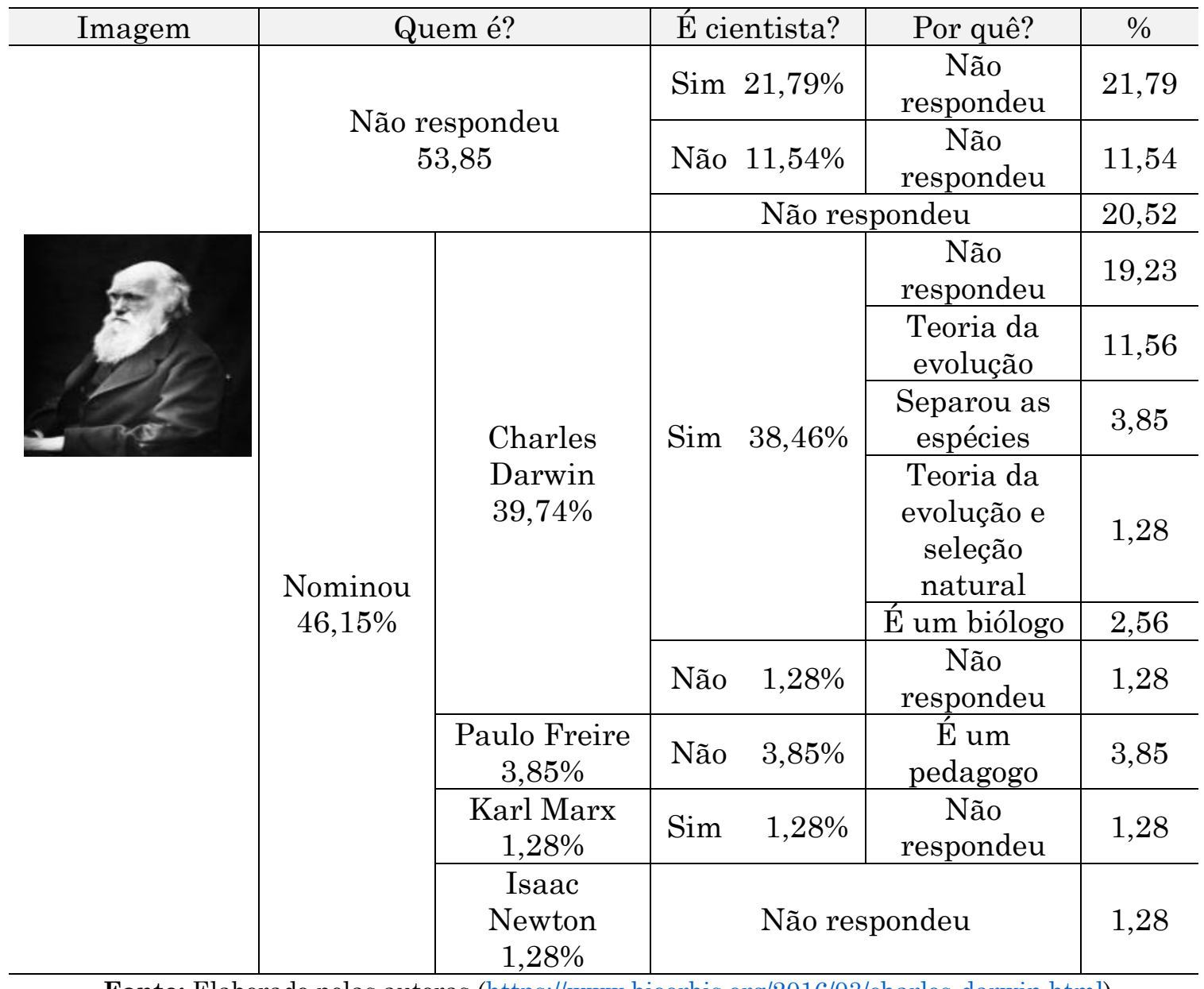

Fonte: Elaborado pelas autoras (https://www.bioorbis.org/2016/03/charles-darwin.html).

Analisando a primeira imagem, podemos perceber que desde criança, Charles Darwin talvez já demostrasse interesse e encantamento pela natureza. A maioria dos entrevistados $93,60 \%$ não soube responder sobre quem se tratava na imagem. $\mathrm{O}$ mesmo ocorreu para a segunda imagem, em que o cientista aparece com sua filha no colo. De fato, estas duas imagens não são comuns entre livros didáticos. Ele apenas foi reconhecido na terceira imagem, comumente ilustrada em materiais educativos; porém, cabe salientar, que mesmo nesta ilustração amplamente difundida, o percentual de identificação, foi restrito $(39,74 \%)$.

Quando questionados se as imagens apresentadas poderiam se tratar de um cientista, foi igualmente significativo entre os participantes esta 
negação, embora os argumentos não foram significativos. Quando nominaram, foram citados Allan Kardec, Albert Einstein e D. Pedro II para a primeira imagem, sendo apenas Albert Einstein reconhecido como cientista. Já na segunda imagem, foram citados quatro nomes: Gregor Mendel, Carl Marx, Neil Young e Dom Pedro I; porém, igualmente, os resultados não apontaram nenhum conhecimento sobre eles, apenas citaram seus nomes. É interessante, que embora não reconhecessem a imagem de Darwin com a filha, apontaram não poder se tratar de um cientista. Tal afirmação possivelmente está associada à imagem equivocada e reducionista que se tem de cientista. Como um indivíduo sozinho, isolado e que não possui uma família, pois se dedica apenas às pesquisas.

Apenas a última imagem, tradicionalmente divulgada em materiais didáticos, foi considerada em parte, um cientista. Nesta figura, Darwin aparece em sua clássica fotografia preta e branca, onde está mais velho e um tanto quanto "barbudo". Essa é uma das imagens mais comuns quando Darwin é referenciado, e os resultados obtidos confirmam o fato. Os alunos atribuíram a Darwin, contribuições como: "Elaborou a teoria da evolução"; "Separou as espécies"; e, "Elaborou a teoria da evolução e seleção natural". Apesar de ocorrerem as referências aos seus feitos, do total de alunos que o reconheceu metade dos participantes não sabiam por que se tratava de um cientista, não tendo citado nenhuma contribuição do mesmo, ou seja, não reconhecem seus feitos $(19,23 \%)$, apesar de reconhecerem esta imagem $(39,74 \%)$.

Rios (2008) ao descrever Charles Darwin, afirma que a contribuição deste cientista para o desenvolvimento do conhecimento humano vai muito além das contribuições para o entendimento da evolução, como um fato da ciência. Ele foi pioneiro na geologia, criando teorias importantes para o surgimento de ilhas oceânicas e explicações corretas para os mecanismos que geram os movimentos ascendentes da Cordilheira dos Andes. Também iniciador da etologia, ciência que estuda o comportamento dos animais. Além disso, pode ser considerado o mentor da moderna ecologia, por ter 
criado os conceitos de "nicho ecológico" e "ecossistema", ao afirmar que cada espécie ocupa um lugar determinado (nicho) na "economia da natureza" (ecossistema). Na taxonomia, ele fez contribuições notáveis, criando os conceitos de "espécies em estado nascendi" e de "espécie fóssil".

Ridley (2006) afirma que a seleção natural é a explicação de Darwin para a evolução. Assim sendo, as espécies mais bem adaptadas ao ambiente terão mais sucesso na sobrevivência e consequentemente melhores resultados na reprodução e geração de descendentes.

Seleção natural é o nome dado a qualquer diferença consistente (não aleatória) entre organismos portadores de alelos ou genótipos diferentes quanto à sua taxa de sobrevivência ou de reprodução (é, seu valor adaptativo), devido a diferenças quanto a uma ou mais características. Na maioria dos casos, há circunstâncias ambientais que influem na determinação de qual variante terá maior valor adaptativo. (FUTUYMA, 2002, p.10).

Ainda na última imagem de Darwin, foi citado Paulo Freire (3,85\%), não sendo considerado um cientista e sim um pedagogo. Paulo Freire foi um dos pensadores mais notáveis na história da pedagogia mundial. Propôs contribuições como educador, pedagogo e filósofo brasileiro. Paulo Freire é um cientista e consequentemente pesquisador importante, na área da educação. Para fechar o quadro de resultados do Darwin, Karl Marx foi citado por um aluno (1,28\%) sendo que esse foi considerado um cientista. Este teve notáveis contribuições como sociólogo e filósofo. Isaac Newton também foi citado por um aluno que não o considerou um cientista e nem atribuiu justificativa a resposta.

Quando foram questionados com a imagem associada ao nome (Tabela 5), os alunos mostraram ter conhecimento apenas sobre o nome (82,05\%), já que a imagem não foi reconhecida (53,85\%). Ao serem questionados sobre o que sabiam a respeito do cientista, os participantes demonstraram ter 
informações sobre algumas de suas contribuições, mais especificamente a teoria da evolução e seleção natural. Embora, como já discutido anteriormente, suas contribuições vão muito além da evolução. Para Rios (2008, p.67), devemos descrever Charles Darwin como um "Naturalista, biólogo, etólogo, taxonomista, geólogo, ecólogo e, não obstante, pai da biogeografia”. Embora, devemos destacar que este último termo é bastante controverso, pois associarmos qualquer estudo a um indivíduo único e apontarmos como "pai" de uma área, é controverso, quando entendemos que a ciência se constrói em coletividade e que muitos pesquisadores contribuem para a sistematização de um pensamento.

TABELA 6: Frequência para o reconhecimento de imagens do cientista Darwin, com a identificação.

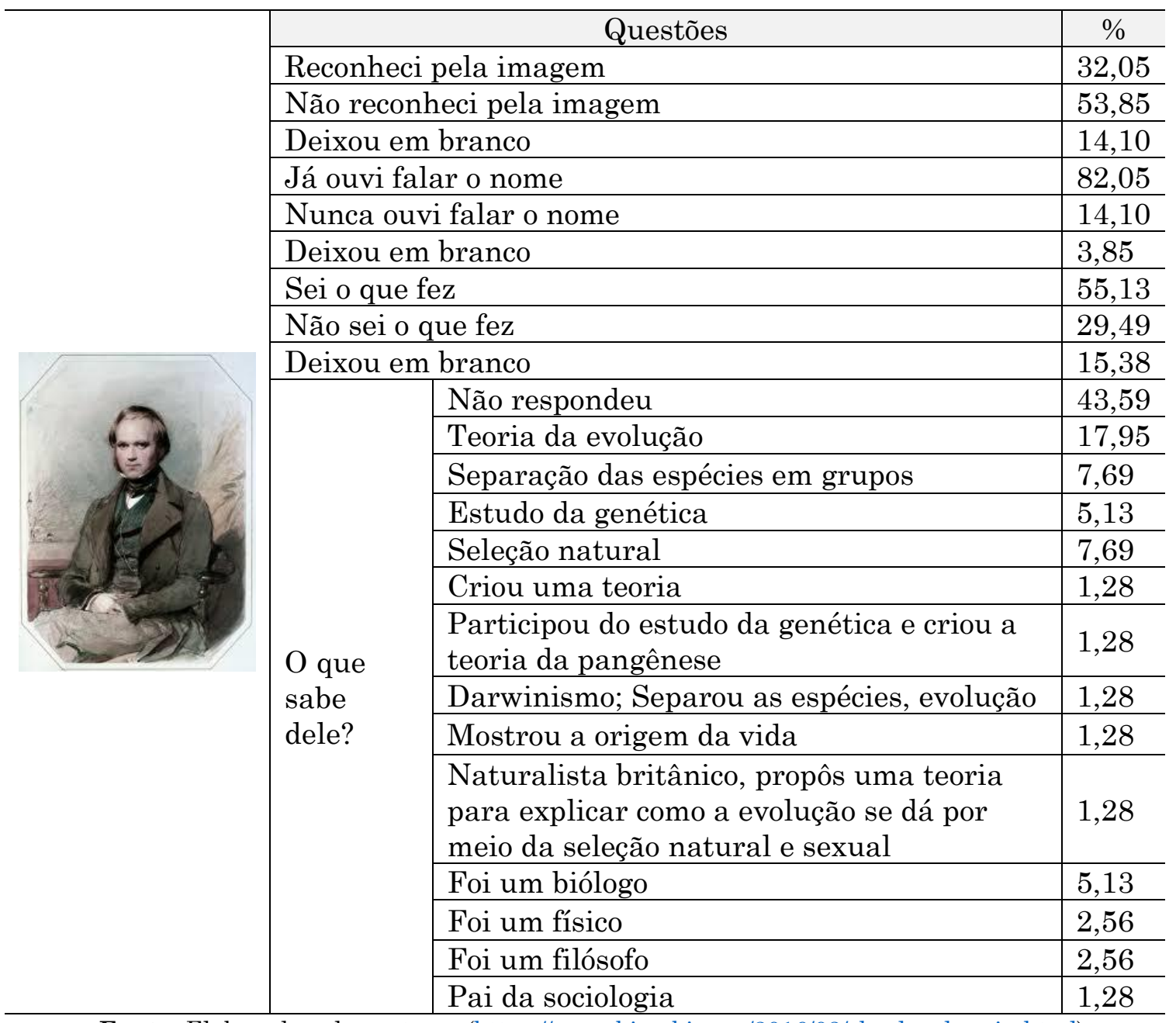

Fonte: Elaborada pelas autoras (https://www.bioorbis.org/2016/03/charles-darwin.html) 
Conforme Domingues, Sá e Glick (2003), Darwin foi um dos principais cientistas a contribuir para a compreensão dos fenômenos que explicam a evolução, sendo o conjunto de suas teorias evolutivas nomeada de "Darwinismo". Ele foi quem afirmou que os seres vivos, inclusive o homem, descendem de ancestrais comuns, que se modificam ao longo do tempo.

Para Darwin propor a teoria da evolução das espécies, ele trabalhou muito viajando por diferentes lugares recônditos do nosso planeta, onde observava, media, testava e analisava tudo ao seu redor, para então ir construindo seu conhecimento. Ainda, lia e pesquisava muito, levando em consideração os estudos já realizados pelos seus contemporâneos, como Georges-Louis Leclerc, Conde de Buffon, que foi o primeiro naturalista a tratar do tema evolução de um modo essencialmente científico.

No que diz respeito à resposta "Separação das espécies" (7,69\%), interpretamos estar relacionada à filogenia, a proposição de Darwin sobre a árvore da vida, em que demonstra os elos entre as diferentes espécies e a separação delas em distintos ramos.

Apenas 1,28\% dos alunos responderam sobre a seleção sexual. Para Nicolini e Waizbort (2013), Darwin sugeriu que a seleção sexual foi justamente o mecanismo que ocorreu para solucionar alguns pontos que não estavam claros antes. Um fenótipo pode ser mais vantajoso na disputa por um parceiro sexual, fazendo com que essa característica se perpetue ao longo do tempo, mesmo esse atributo não sendo diretamente útil a sobrevivência, mas sim vantajoso na reprodução.

Quando citado "Participou do estudo da genética e criou a teoria da pangênese" (1,28\%), Almeida e Rocha Falcão (2005) sinalizam que Darwin tinha sim conhecimento dos estudos em genética de Mendel. Assim, Charles Darwin usava a teoria já existente da pangênese para explicar a transmissão de caracteres adquiridos.

Apesar de apenas 1,28\% dos participantes apontarem que o cientista foi responsável por "Mostrar a origem da vida", é importante destacar que 
ainda há confusão entre os estudos sobre a origem da vida e a evolução. Darwin explicava como poderíamos ter surgido de um ancestral comum, porém, nunca publicou nada a respeito de como o primeiro ancestral se originou.

\section{Conclusão}

Os resultados revelam que o uso de imagens ainda é um pouco restrito em sala de aula, ou muito pouco explorado, uma vez que os alunos não mostraram reconhecer de forma significativa as imagens oferecidas, mesmo quando as mais comuns em materiais didáticos apareceram. Geralmente os alunos acabam tendo acesso apenas às imagens presentes nos livros didáticos, os quais prezam mais por imagens explicativas, de um fenômeno ou estrutura, e então, os cientistas são na maioria das vezes, somente citados pelo nome, data de nascimento/falecimentos, sem maiores informações sobre suas contribuições e contexto sócio histórico.

Embora os alunos, quando citado o nome do cientista, citaram algumas de suas contribuições, ainda foram muito sutis e com muitas informações reducionistas e até errôneas. Apresentar de forma adequada e ampliada a História da Ciência pode contribuir como um dispositivo didático útil, tornando o ensino da ciência a nível médio mais interessante, além de facilitar a aprendizagem e desconstruir mitos relacionados à ciência.

\section{Referências}

ALMEIDA, A.V. e ROCHA FALCÃO, T. J. A estrutura histórico-conceitual dos programas de pesquisa de Darwin e Lamarck e sua transposição para o ambiente escolar. Ciência \& Educação, Bauru, v. 11, n. 1, p. 17-32, 2005.

ALMEIDA, V. e ROCHA FALCÃO, J. T. R. As teorias de Lamarck e Darwin nos livros didáticos de Biologia no Brasil. Ciência \& Educação (Bauru), vol. 16, núm. 3, 2010, pp. 649-665.

BARDIN, L. Análise de conteúdo. São Paulo: Edições 70, 2011. 
BIZZO, N. M. V. Ensino de evolução e história do darwinismo. 1991. 312f. Tese (Doutorado em Educação) - Universidade de São Paulo, São Paulo, 1991.

BOGDAN, R. C. e BIKLEN, S. K. Investigação Qualitativa em Educação: uma introdução à teoria e aos métodos. Porto: Porto Editora, 2006. 336 pp.

BRANDO, F. da R.; ANDRADE, M. A. B. S.; MEGLHIORATTI, F. A.; CALDEIRA, M. A. Contribuições da epistemologia e da história da ecologia para a formação de professores e pesquisadores. Filosofia e História da Biologia, v. 7, n. 2, p. 181-200, 2012.

DOMINGUES, H. M.B., SÁ, M.R.., GLICK, T. (Orgs). A recepção do Darwinismo no Brasil [online]. História e saúde collection. Rio de Janeiro: Editora FIOCRUZ, 2003, 189 p.

DUARTE, B. et al. A importância da história da ciência na perspectiva dos alunos de ensino médio: a investigação em uma escola no portal do triângulo mineiro. Anais... In: XV Encontro Nacional de Ensino de Química, Brasília, 2010.

ENGELMANN, G. L. Percepção de cientistas e da história da ciência em livros didáticos de química. 2017. 235f. Dissertação. Programa de Pós-Graduação em Educação, Universidade Estadual do Oeste do Paraná/UNIOESTE - Campus de Cascavel, Paraná.

EL-HANI, C. N. Notas sobre o ensino de história e filosofia da ciência na educação científica de nível superior. In: SILVA, C. C. Estudo de História e Filosofia das Ciências: subsídios para aplicação no ensino. São Paulo: Livraria da Física, p. 3-21, 2006.

FRADE, D. K. G. A natureza da ciência em conteúdos de genética nos livros didáticos de biologia do ensino médio e sua influência no desenvolvimento do saber científico. 2014. 48f. Monografia. Curso de Ciências Biológicas. Universidade Federal da Paraíba, João Pessoa.

FUTUYMA, D. J. Evolução, ciência e sociedade. São Paulo: Sociedade Brasileira de Genética, 2002.

KOSMINSKY, L. e GIORDAN, M. As visões de ciência e sobre cientista entre estudantes de ensino médio. Química Nova na Escola, n 15, p. 11-18, maio 2002.

LAMARCK, J. P. B. A. M. (1835-1840). Histoire Naturelle des Animaux sans Vertèbres. 2ème édition révue et augmentée de notes présentant les faits nouveaux dont la Sciences'est enrichie jusqu'à ce jour, par M. M. G. H. Deshayes et H. Milne Edwards. 11 vols. Paris: Baillière.

MARTINS, L. A. C. P. A. A teoria da progressão dos animais, de Lamarck. Rio de Janeiro/São Paulo: Booklink/Fapesp/GHTC-Unicamp, 2007.

MARTINS, L. A. C. P. Lamarck e evolução orgânica: as relações entre o vivo e o não-vivo. Ciência \& Ambiente, v. 36, p. 11-21, 2008. 
MARTINS, L. A. C. P.e BAPTISTA, A. M. H. Lamarck, evolução orgânica e tempo: algumas considerações. Filosofia e História da Biologia. 2007.

MARTINS, R. A. Introdução: a história das Ciências e seus usos na Educação. In: SILVA, C. C. (Org). Estudos de história e filosofia das ciências: subsídios para aplicação no ensino. São Paulo: Editora Livraria da Física, p. 17-30, 2006.

MELZER, M. e AIRES, J. A. A História do desenvolvimento da teoria atômica: um percurso de Dalton a Bohr. Amazônia, Revista de Educação em Ciências e Matemática, v.11 (22) Jan-Jun 2015. p.62-77.

MOURA, B. A. O que é natureza da Ciência e qual sua relação com a História e Filosofia da Ciência? Revista Brasileira de História da Ciência, Rio de Janeiro, v. 7, n. 1, p. 32-46, jan/jun, 2014.

NICOLINI, L. B. e WAIZBORT R. F. Plumas, cantos e mentes: Darwin, a seleção sexual e o ensino da teoria da evolução. Revista Brasileira de Pesquisa em Educação em Ciências. Vol. 13, No2, 2013. 187.

NOGUEIRA-MARTINS, M. C. Considerações sobre a metodologia qualitativa como recurso para o estudo das ações de humanização em saúde. Saúde e Sociedade. v.13, n.3, p.44-57, set-dez 2004.

RIDLEY, M. Evolução. São Paulo: Editora Artmed, 3ª ed. 2006.

RIOS, R. I. Darwin: muito famoso e pouco lido. Ciência Hoje, vol. 42, n 250, julho, 2008. pg. 66-68.

ROQUE, I. R. Sobre girafas, mariposas, corporativismo científico e anacronismos didáticos. Ciência Hoje, São Paulo, v. 34, n. 200, p. 64-67, 2003.

SEQUEIRA, M.; LEITE, L. A História da Ciência no Ensino Aprendizagem das Ciências. Revista Portuguesa de Educação. Universidade do Minho: Portugal. p.2940, 1988.

SILVA, B. V. C. Young fez, realmente, o experimento da fenda dupla? Latin American Journal of Physics Education., v. 3, p. 280-287, 2009.

SILVA, B. V. C. e MARTINS, A.F.P. Júri simulado: um uso da História e da Filosofia da Ciência no ensino da Óptica. Física na Escola, v. 10, p. 17-20, 2009.

SILVA, E. N.; TEIXEIRA, R. R. P. A história da ciência nos livros didáticos de física. Revista Tecnologia e Tendências. v. 8, n. 1 Janeiro / Junho, 2009. 